Check for updates

Cite this: RSC Adv., 2017, 7, 54644

\title{
Electrospun polyacrylonitrile nanofiber mat protected membranes for vanadium flow batteries
}

\author{
Lihong Yu, (D) *a Feng Lin, ${ }^{a}$ Ling $X u^{a}$ and Jingyu $X i$ (D) *b
}

A cheap, efficient and durable proton exchange membrane is essential for vanadium flow batteries (VFB). The sulfonate poly(ether ether ketone) (SPEEK) membrane is a leading candidate to replace the widely used Nafion series membranes because of high proton to vanadium ion selectivity and low-cost. However, poor chemical/mechanical stability still hinders the practical application of the SPEEK membrane in VFB. Herein, we report a simple and robust strategy by using an electrospun polyacrylonitrile (PAN) nanofiber mat as a protection layer to improve the stability of the SPEEK membrane. The PAN nanofiber mat can prevent the damage to the SPEEK membrane from the vanadium electrolytes, graphite (carbon) felt electrodes and sealing gaskets, without affecting the VFB performance. Therefore, the PAN nanofiber mat-SPEEK-PAN nanofiber mat (P-S-P) sandwich membrane demonstrates excellent rate performance and superior cycling stability over 1000 charge/ discharge cycles at a current density of $120 \mathrm{~mA} \mathrm{~cm} \mathrm{~cm}^{-2}$

Received 5th November 2017 Accepted 24th November 2017

DOI: 10.1039/c7ra12145h

rsc.li/rsc-advances as incorporating inorganic fillers, ${ }^{\mathbf{2 6 , 2 7}}$ blending with other polymers, ${ }^{28,29}$ and reinforcing by porous skeletons. ${ }^{30}$ Compared with above microscopic modification approaches, macroscopic protection is another effective method. In our previous work, we have demonstrated that the cycling stability of the SPEEK membrane can be greatly enhanced by using 3D porous, hydrophilic and particularly stable poly(tetrafluoroethylene) (PTFE) film as a protective layer on both sides. ${ }^{31}$ This novel sandwich design would thoroughly change the interactions between PEM and electrolytes, electrodes and sealing materials. The resulted PTFE-SPEEK-PTFE sandwich membrane exhibited superior cycling performance over 1000 charge/discharge cycles at $80 \mathrm{~mA} \mathrm{~cm}^{-2}$ with stable CE (98.5\%) and low capacity decay rate $(0.059 \%$ per cycle).

Although the porous PTFE film protection approach has proved to be effective to enhance the durability of the SPEEK membrane, the relatively high cost $\left(\$ 50\right.$ per $\left.\mathrm{m}^{2}\right)$ of the porous PTFE film hinder its practical application in VFB. Therefore, we hope to find cheaper porous structured materials to replace the expensive porous PTFE film. Polyacrylonitrile (PAN) has been utilized in many fields due to its low-cost, good mechanical property and chemical stability. ${ }^{28}$ For example, PAN has been widely studied as a raw material for electrospinning, ${ }^{32-34}$ by which the PAN nanofiber mat can be fabricated with tunable fiber size, mat thickness and porosity.

In this study, we use the electrospun PAN nanofiber mat as the protective layer of the SPEEK membrane (denoted as P-S-P), as shown in Fig. 1. The three parts are stacked together by physical contact. The PAN nanofiber mat can prevent the external damage to the SPEEK membrane from the vanadium electrolytes, graphite (carbon) felt electrodes and sealing
${ }^{a}$ School of Applied Chemistry and Biological Technology, Shenzhen Polytechnic, Shenzhen 518055, China.E-mail: yulihong@szpt.edu.cn

${ }^{b}$ Institute of Green Chemistry and Energy, Graduate School at Shenzhen, Tsinghua University, Shenzhen 518055, China.E-mail: xijy@tsinghua.edu.cn 


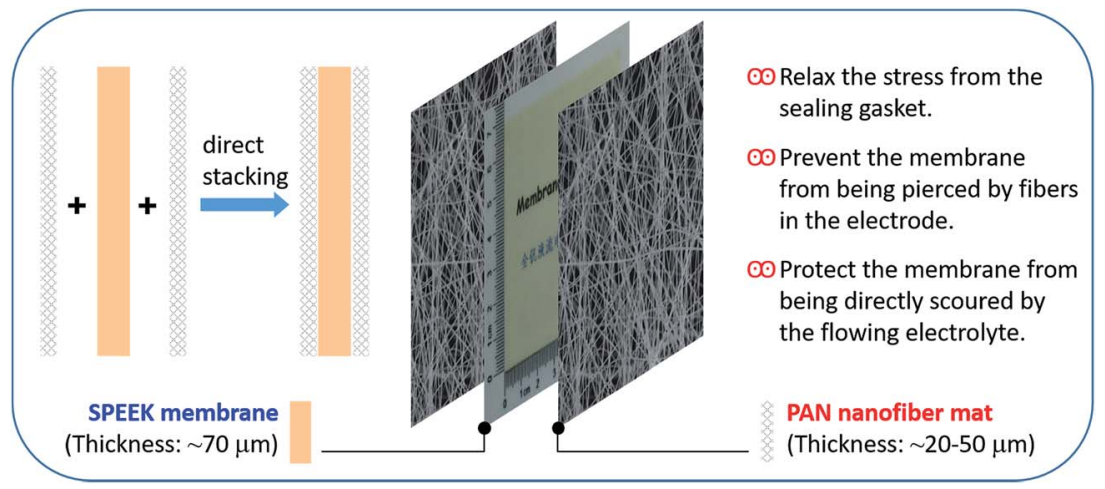

Fig. 1 Schematic representation and proposed protection mechanism of PAN nanofiber mat.

gaskets. The effect of PAN nanofiber mat on the ion transport properties, VFB rate performance and long-term cycling stability of the SPEEK membrane are studied in detail, and compared with the widely used Nafion 115 membrane. The thickness impact of PAN nanofiber mat on VFB performance of $\mathrm{P}-\mathrm{S}-\mathrm{P}$ membranes is also investigated.

\section{Experimental}

\subsection{Materials}

Poly(ether ether ketone) (PEEK 450G) was purchased from Victrex. Polyacrylonitrile (PAN, $\left.M_{\mathrm{w}} \sim 150000\right)$ was purchased from Sigma-Aldrich. Nafion 115 membrane (Nafion) was purchased from DuPont. PAN based graphite felt (GF, $5 \mathrm{~mm}$ of thickness) was purchased from Gansu Haoshi Carbon Fiber Co., Ltd. Other chemicals were of analytical grade and used without further purification.

\subsection{Preparation and characterization of PAN mat}

The PAN nanofiber mat was fabricated on an electrospinning instrument (TONGLI TL-01). The electrospinning solution was obtained by dissolving PAN (10 wt\%) in DMF at $60{ }^{\circ} \mathrm{C}$ under stirring for $10 \mathrm{~h}$, and the flow rate was controlled at $1 \mathrm{~mL} \mathrm{~h}^{-1}$ by a syringe pump. The detailed electrospun parameters were applied as follow: a high voltage of $15 \mathrm{kV}$, a needle-to-collector distance of $15 \mathrm{~cm}$, a needle moving speed of $1 \mathrm{~cm} \mathrm{~min}{ }^{-1}$ within a horizontal range of $10 \mathrm{~cm}$, and a collector rotating speed of $200 \mathrm{rpm}$. The PAN nanofiber was deposited on an Al foil, which was stuck onto the cylindrical collector. The morphology of the obtained PAN nanofiber mat was observed by scanning electron microscopy (SEM, Hitachi S-4800).

\subsection{Preparation and characterization of SPEEK membrane}

SPEEK membrane was prepared according to our previous work. ${ }^{21}$ Briefly, $25 \mathrm{~g}$ PEEK pellets were sulfonated in $250 \mathrm{~mL}$ $\mathrm{H}_{2} \mathrm{SO}_{4}(98 \%)$ at $50{ }^{\circ} \mathrm{C}$ for $2.5 \mathrm{~h}$, washed in $0{ }^{\circ} \mathrm{C}$ deionized water, and dried at $100{ }^{\circ} \mathrm{C}$. Then, $1.5 \mathrm{~g}$ of the obtained SPEEK resin was dissolved in $10 \mathrm{~mL}$ DMF solvent to form homogeneous casting solution. Afterwards, the SPEEK solution was cast on glass plate and then dried at $60{ }^{\circ} \mathrm{C}$ for $24 \mathrm{~h}$. Finally, the SPEEK membrane was peeled off and then soaked in $1 \mathrm{M} \mathrm{H}_{2} \mathrm{SO}_{4}$ and deionized water for $24 \mathrm{~h}$, respectively. The thickness of the SPEEK membrane was $70 \mu \mathrm{m}$ in wet state, and the degree of sulfonation was 0.61 based on the $\mathrm{H}^{+}$titration method. ${ }^{31}$ Vanadium ion crossover of the membrane was measured on a membrane separated diffusion cell, ${ }^{28}$ and the change of $\mathrm{VO}^{2+}$ concentration was monitored on a UV-vis spectrometer (Leng Guang 752S).

\subsection{Single cell evaluation}

The configuration of a VFB single cell is the same as in our previous work. ${ }^{26,28}$ The digital photo and detailed parameters of the VFB are listed in Fig. 2. A Nafion 115 membrane (acid boiled) ${ }^{16}$ and two graphite felts (thermal activated at $420{ }^{\circ} \mathrm{C}$ for $10 \mathrm{~h})^{35}$ were used as separator and electrodes, respectively. The effective area of membrane and electrode is $25 \mathrm{~cm}^{2}$ $(5 \mathrm{~cm} \times 5 \mathrm{~cm})$. Two solutions of $50 \mathrm{~mL}$ vanadium electrolyte $\left(1 \mathrm{M} \mathrm{V}^{3+}+1 \mathrm{M} \mathrm{VO}^{2+}+2.0 \mathrm{M}^{2} \text { free } \mathrm{H}_{2} \mathrm{SO}_{4}\right)^{36}$ were used as initial catholyte and anolyte, respectively. Both electrolyte tanks were purged with nitrogen gas for $10 \mathrm{~min}$ and then sealed prior to the test. The charge/discharge of the VFB was controlled by a battery testing system (Neware CT-30085V6A). The ambient temperature was controlled at $26 \pm$ $2{ }^{\circ} \mathrm{C}$. Rate performance was evaluated under the current densities range from $40 \mathrm{~mA} \mathrm{~cm}{ }^{-2}$ to $200 \mathrm{~mA} \mathrm{~cm}{ }^{-2}$. Cycling performance was conducted under the current density of $80 \mathrm{~mA} \mathrm{~cm}^{-2}$. Super long-term cycling stability was performed at the current density of $120 \mathrm{~mA} \mathrm{~cm}{ }^{-2}$. The VFB was charged to the $50 \%$ state of charge (SOC) at a current density of $60 \mathrm{~mA} \mathrm{~cm}{ }^{-2}$ to conduct the self-discharge test.

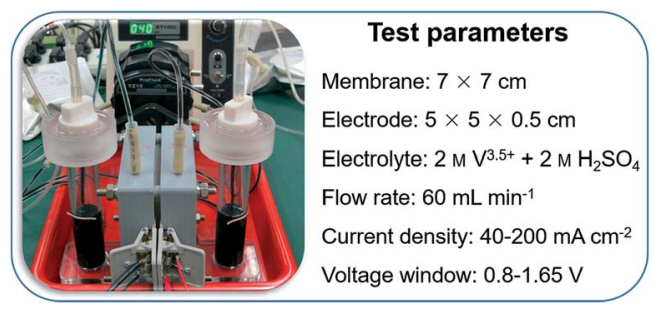

Fig. 2 Digital photo and test parameters of the VFB single cell. 


\section{Results and discussion}

Fig. 3a shows the photo of the electrospinning equipment. An $\mathrm{Al}$ foil (width $=20 \mathrm{~cm}$ ) was stuck onto the cylindrical collector to deposit the PAN nanofibers. The average thickness of the PAN nanofiber mat was controlled by tailoring the electrospinning time. For instance, the PAN nanofiber mat with thickness of 20, 40 , and $50 \mu \mathrm{m}$ were obtained at 2,4 , and $5 \mathrm{~h}$ of electrospinning, respectively. The obtained PAN nanofiber mat was cut into the size of $7 \times 7 \mathrm{~cm}$, the same as that of the SPEEK membrane (Fig. 2), to fabricate the P-S-P sandwich membrane (Fig. 1). As shown in Fig. 3b, the as-prepared PAN nanofiber mat is homogeneous, white and opaque. The fiber morphology of the PAN nanofiber mat was observed by SEM and shown in Fig. 3c and $\mathrm{d}$. The fiber direction is randomly distributed, forming a non-woven porous network structure. Under our electrospinning parameters, the diameter distribution of the nanofiber is very narrow and the average diameter is about $300 \mathrm{~nm}$. In addition, the distance between the PAN nanofibers $(1-8 \mu \mathrm{m})$ is smaller than the fiber diameter $(10-15 \mu \mathrm{m})$ in graphite (carbon) felt electrodes. ${ }^{\mathbf{8}, 31}$ This ensures that the PAN nanofiber mat protects the SPEEK membrane against the puncturing of the fibers in graphite (carbon) felt electrodes.

The porosity of the PAN nanofiber mat was determined by a simple drainage method since the PAN has excellent hydrophilicity. ${ }^{37}$ First, the apparent volume $\left(V_{1}\right)$ of the PAN nanofiber mat was calculated from its length, width and thickness. Then, the PAN nanofiber mat was immersed into deionized water and evacuated for $1 \mathrm{~h}$ to ensure the water thoroughly occupying the fiber gaps of the mat. At last, the volume increase of the measuring cylinder was calculated, which is the actual volume of PAN nanofiber mat $\left(V_{2}\right)$. Then, the porosity $(P)$ can be calculated by the equation: $P=\left(V_{1}-V_{2}\right) / V_{1}$. It is found that the thickness of the PAN nanofiber mat has no obvious relationship with the porosity of the mat. The porosity of all PAN nanofiber mats is about 0.84 , which is beneficial to allow the good contact
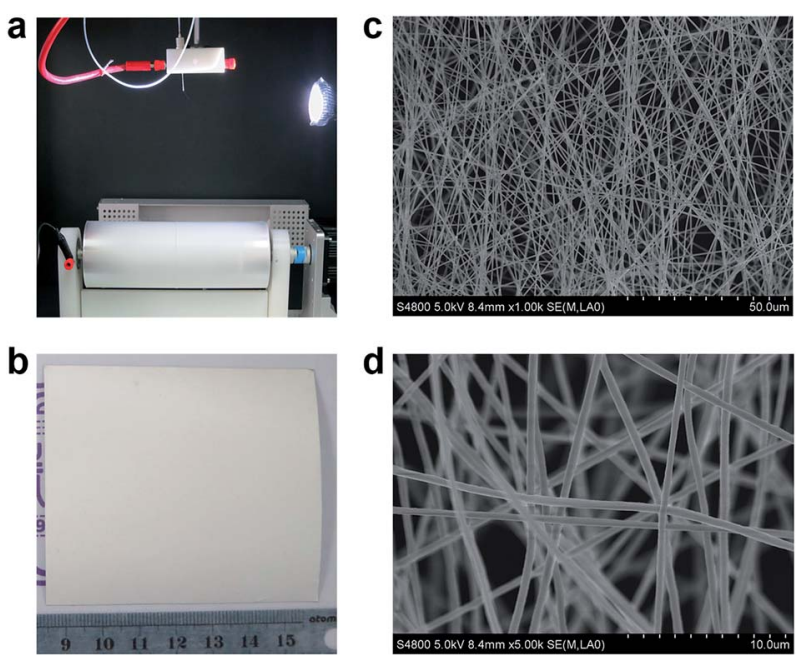

Fig. 3 Preparation and characterization of the PAN nanofiber mat: (a) photo of the electrospinning setup, (b) photo of the PAN nanofiber mat, (c and d) SEM images of the PAN nanofiber mat. between vanadium electrolyte and SPEEK membrane during VFB operation.

Vanadium ion crossover through the membrane is one of the key problems in VFB, resulting in low CE and rapid capacity fading. ${ }^{9}$ Therefore, the effect of PAN nanofiber mat (thickness $=$ $20 \mu \mathrm{m}$ ) on the ion transport properties of the SPEEK membrane was evaluated firstly. The widely used Nafion 115 membrane was also tested and used as a benchmark. Fig. 4a shows the $\mathrm{VO}^{2+}$ crossover plots of various membranes. Nafion membrane exhibits very fast $\mathrm{VO}^{2+}$ permeation rate because of the fully opened micellar channels during acid boiling process. ${ }^{\mathbf{1 0}, 17}$ The large size of micellar channels for Nafion membrane will lead to a fast transport of proton and vanadium ions $\left(\mathrm{V}^{2+}, \mathrm{V}^{3+}, \mathrm{VO}^{2+}\right.$ and $\mathrm{VO}_{2}{ }^{+}$) simultaneously, resulting in low proton/vanadium ion selectivity. On the contrary, the SPEEK membrane demonstrates extremely low $\mathrm{VO}^{2+}$ permeation rate due to its narrow micellar channels. ${ }^{21,38}$ After $72 \mathrm{~h}$, the final concentration of $\mathrm{VO}^{2+}$ in the right reservoir of the diffusion cell (inset of Fig. 4a) is $0.168 \mathrm{M}$ and $0.009 \mathrm{M}$ for Nafion and SPEEK membrane, respectively. With the protection of PAN nanofiber mat, the P-S-P sandwich membrane shows slightly lower $\mathrm{VO}^{2+}$ permeation rate than that of pristine SPEEK membrane. This phenomenon may be due to that the PAN nanofiber mat can hold a relatively stable electrolyte layer, which will not be disturbed by the agitation in both reservoirs of the diffusion cell. The same vanadium ion crossover trend is also observed from the self-discharge curves of various membranes, as shown in Fig. $4 \mathrm{~b}$. The initial open circuit voltage (OCV) of SPEEK and P-S-P membranes based VFBs is higher than that of the Nafion membrane because of lower permeation rate of vanadium ions during charge process. The OCV values of all VFBs steadily decrease with time before $1.25 \mathrm{~V}$ and then drop sharply to $0.8 \mathrm{~V}$, which is due to the disappearance of $\mathrm{VO}_{2}{ }^{+}$in positive half-cell. ${ }^{16}$ The time to reach $0.8 \mathrm{~V}$ are $36.8 \mathrm{~h}, 128.1 \mathrm{~h}$ and $147.2 \mathrm{~h}$ for Nafion, SPEEK and P-S-P membranes, respectively.

All aforementioned membranes were subsequently assembled into VFB single cells to investigate the effect of the PAN nanofiber mat on the SPEEK membrane performances in VFB. The charge/discharge tests were conducted at the current densities range from $40 \mathrm{~mA} \mathrm{~cm} \mathrm{~cm}^{-2}$ to $200 \mathrm{~mA} \mathrm{~cm}{ }^{-2}$. Fig. $5 \mathrm{a}$ illustrates the charge/discharge curves of VFBs with various membranes at a moderate current density of $80 \mathrm{~mA} \mathrm{~cm}{ }^{-2}$. The VFBs with SPEEK membrane and $\mathrm{P}-\mathrm{S}-\mathrm{P}$ sandwich membrane present nearly the same charge/discharge curves, indicating that the PAN nanofiber mat has no negative effect on the VFB performance of the SPEEK membrane. The theoretical capacity corresponding to $50 \mathrm{~mL}$ of $2 \mathrm{M}$ vanadium electrolyte is $2.68 \mathrm{~A} \mathrm{~h}$. The VFBs with SPEEK and $\mathrm{P}-\mathrm{S}-\mathrm{P}$ membranes can deliver a discharge capacity of $2.36 \mathrm{~A} \mathrm{~h}$, corresponding to an electrolyte utilization (EU) of $88.1 \%$, significantly higher than that of Nafion membrane (2.20 A h, $82.1 \%$ of EU). This is attributed to the lower vanadium permeation rate of SPEEK based membranes compared to the Nafion membrane (Fig. 4). High EU of SPEEK based membranes helps to increase the energy density, which is essential for practical application of VFB.

Rate performance of the VFBs with various membranes, including coulombic efficiency (CE), voltage efficiency (VE) and 

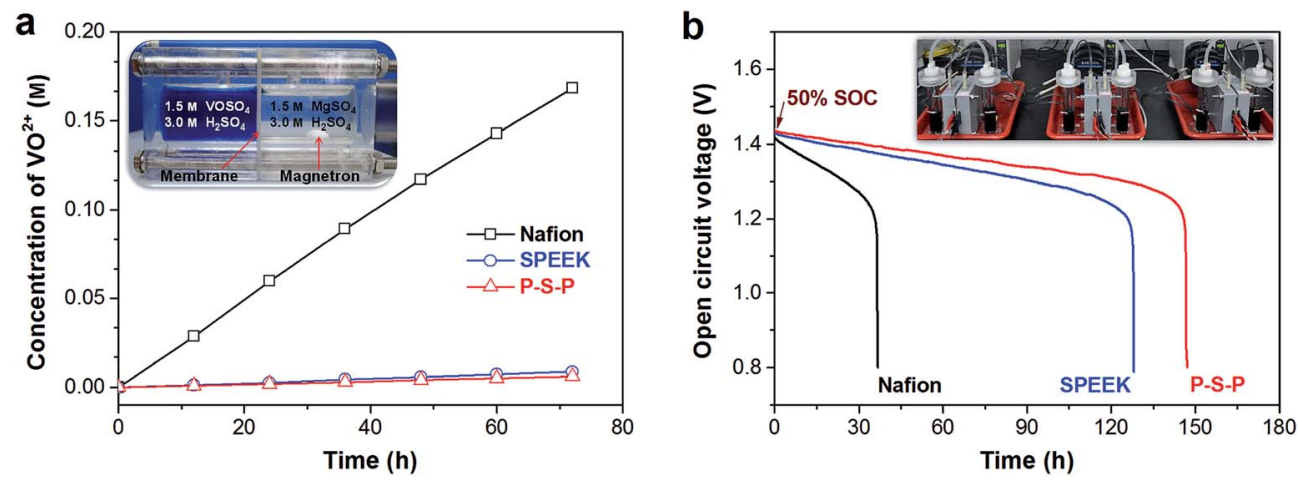

Fig. 4 lon transport properties of various membranes: (a) $\mathrm{VO}^{2+}$ crossover plots, inset shows the photograph of the diffusion cell, (b) selfdischarge curves, inset shows the photograph of three VFBs.

energy efficiency (EE), are shown in Fig. 5b-d. The CE of Nafion based VFB increases from $89.8 \%$ to $94.9 \%$ when the current density elevates from $40 \mathrm{~mA} \mathrm{~cm}{ }^{-2}$ to $200 \mathrm{~mA} \mathrm{~cm}{ }^{-2}$, due to shorter charge/discharge time at higher current density. ${ }^{16}$ SPEEK and P-S-P membranes demonstrate very high CE (98.4\%) even at a low current density of $40 \mathrm{~mA} \mathrm{~cm} \mathrm{~cm}^{-2}$ because of their extremely low vanadium ion crossover. The P-S-P sandwich membrane does not exhibit the expected higher CE than the SPEEK membrane as compared to the vanadium crossover and self-discharge results in Fig. 4. This may be due to two reasons. On one hand, the SPEEK membrane has already own a high CE value $\left(98.4-99.5 \%\right.$ at $\left.40-200 \mathrm{~mA} \mathrm{~cm}^{-2}\right)$. On the other hand, the electrolyte in the PAN nanofiber mat may be affected by the electric field and mass transfer during charge/discharge process. Therefore, SPEEK and P-S-P membranes exhibit very close $\mathrm{CE}$ values at all current densities, as shown in Fig. $5 \mathrm{~b}$. The VE of all VFBs decreases with increasing current density because of the increased polarization (Fig. 5 c) ${ }^{8,39}$ The VE of the SPEEK membrane is slightly lower than that of the Nafion membrane when the current density is higher than $100 \mathrm{~mA} \mathrm{~cm}^{-2}$. This is due to the larger area resistance of the SPEEK membrane than the Nafion membrane ( 0.87 vs. $\left.0.82 \Omega \mathrm{cm}^{2}\right)$. The P-S-P sandwich membrane shows close VE with the SPEEK membrane in the current densities range of $40-100 \mathrm{~mA} \mathrm{~cm} \mathrm{~cm}^{-2}$, indicating that the PAN nanofiber mat has no influence on the VE of the SPEEK membrane at moderate current densities. However, slightly loss of VE can be observed for the P-S-P sandwich membrane when the current density is higher than
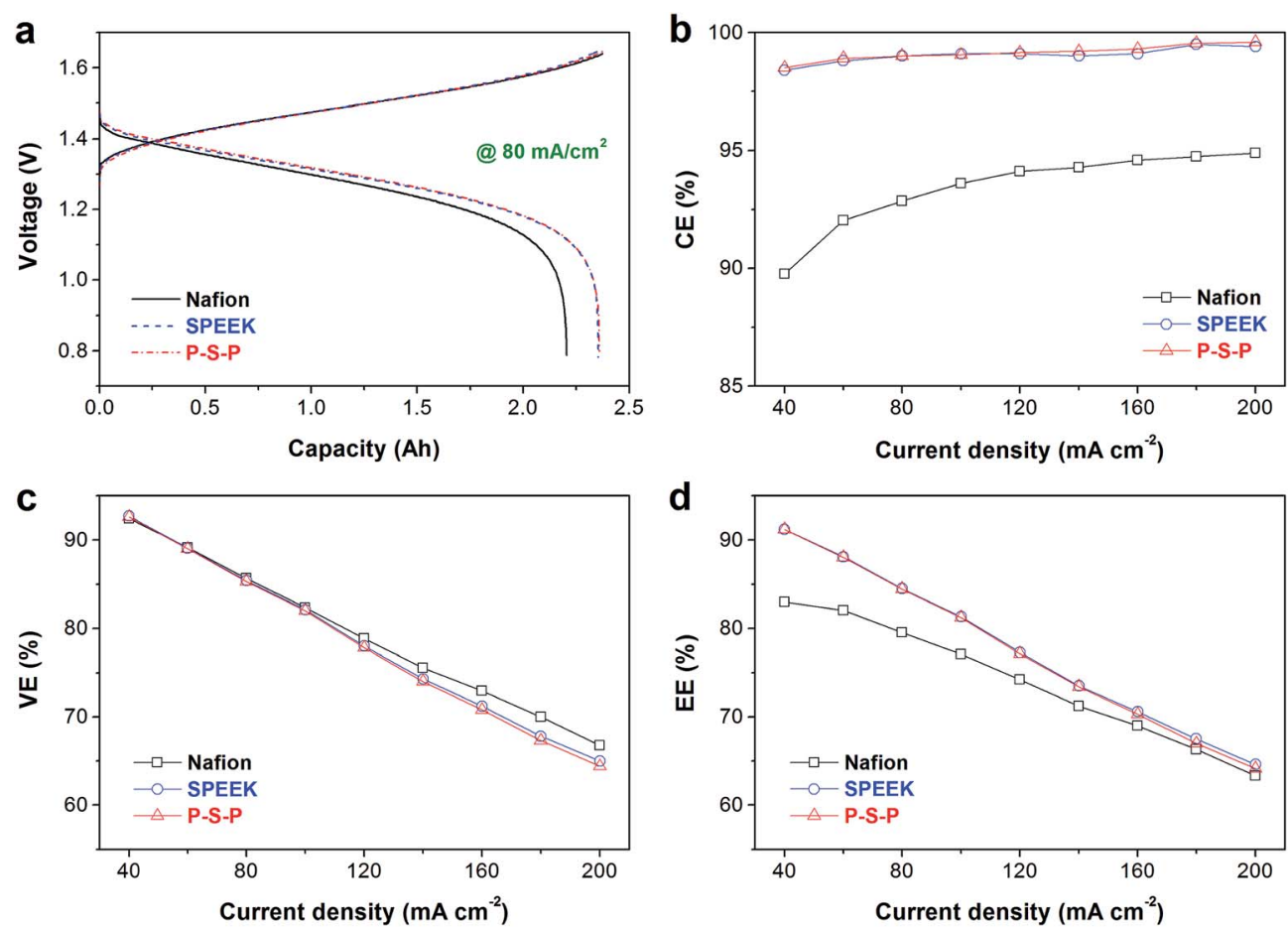

Fig. 5 Rate performance of various membranes: (a) charge/discharge curves at $80 \mathrm{~mA} \mathrm{~cm}^{-2}$, (b) coulombic efficiency, (c) voltage efficiency, (d) energy efficiency. 
$120 \mathrm{~mA} \mathrm{~cm}{ }^{-2}$, suggesting that the PAN nanofiber mat would affect the mass transfer at higher current densities. With the mutual effect of CE and EE, both the SPEEK and the P-S-P membranes demonstrate higher EE than that of the Nafion membrane at all current densities, although their difference decreases with increasing current density (Fig. 5d). The rate performance results clearly show that the PAN nanofiber mat protective layer has no obvious influence on the battery efficiency of the SPEEK membrane.

To reveal the effect of the thickness of the protective layer on the VFB performance of the SPEEK membrane, a series of P-S-P sandwich membranes with various thickness of PAN nanofiber mat (i.e. 20, 40 and $50 \mu \mathrm{m}$ ) were fabricated and assembled into VFBs. The VFBs were evaluated by charging/discharging at current density of $80 \mathrm{~mA} \mathrm{~cm}{ }^{-2}$, and the obtained efficiencies are compared in Fig. 6. Obviously, the thickness of the PAN nanofiber mat has almost no influence on CE and EE of the SPEEK membrane. Therefore, the $20 \mu \mathrm{m}$ thick of PAN nanofiber mat was selected as the protective layer of the SPEEK membrane for subsequent lifespan test.

Fig. 7 shows the cycling performance of VFBs with Nafion, SPEEK and P-S-P membranes at current density of $80 \mathrm{~mA} \mathrm{~cm}^{-2}$. The Nafion membrane exhibits stable CE over 200 cycles because of its extremely high mechanical/chemical stability. ${ }^{\mathbf{1 0 , 3 8}}$ However, charge capacity of Nafion membrane decays very fast and the capacity retention is only $22.9 \%$ after 200 cycles due to serious vanadium crossover issue. ${ }^{9,16}$ For the SPEEK membrane, the CE remains stable and the capacity fading is slow in the first 100 cycles, indicating that the SPEEK membrane is relatively stable for short operation time in VFB. In the subsequent 101154 cycles, the CE reduces gradually and the capacity decays faster, suggesting that the SPEEK membrane began to degrade gradually because of its poor chemical/mechanical stability. ${ }^{25,31}$ Finally, the CE drops sharply at the 155th cycle, indicating that the SPEEK membrane has ruptured. With the protection of PAN nanofiber mat, the $\mathrm{P}-\mathrm{S}-\mathrm{P}$ sandwich membrane demonstrates extremely stable CE over 300 cycles. Meanwhile, the capacity fading of the $\mathrm{P}-\mathrm{S}-\mathrm{P}$ membrane is much slower than that of the Nafion membrane. For instance, after 200 cycles, the capacity

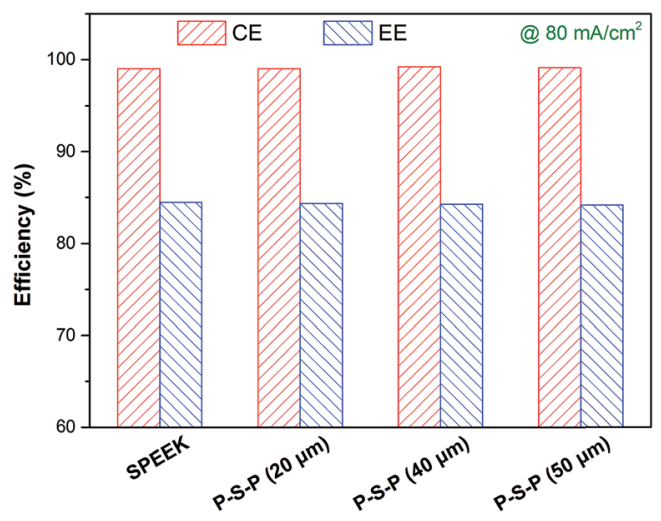

Fig. 6 Thickness impact of the PAN nanofiber mat on VFB performance of various $\mathrm{P}-\mathrm{S}-\mathrm{P}$ membranes at a current density of $80 \mathrm{~mA} \mathrm{~cm}^{-2}$.

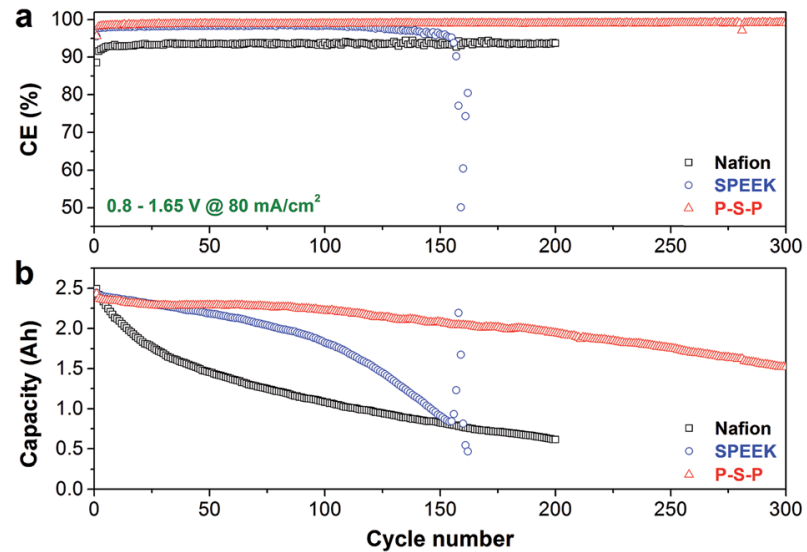

Fig. 7 Cycling performance of various membranes at a current density of $80 \mathrm{~mA} \mathrm{~cm}^{-2}$ : (a) coulombic efficiency, (b) charge capacity fading curves.

retention of the $\mathrm{P}-\mathrm{S}-\mathrm{P}$ membrane is $79.9 \%, 57 \%$ higher than that of the Nafion membrane. Comparing the capacity decay curves of SPEEK and P-S-P membranes (Fig. 7b), it suggests that the PAN nanofiber mat can indeed protect the SPEEK membrane effectively for the VFB application. For different components of the VFB, the protection mechanism may include three aspects: (1) relax the stress from the sealing gasket; (2) prevent the membrane from being pierced by fibers in graphite (carbon) felt electrode; (3) protect the membrane from being directly scoured by the flowing electrolyte.

To further assess the durability of the P-S-P membrane, a super long-term charge/discharge test was conducted over 1000 cycles at a high current density of $120 \mathrm{~mA} \mathrm{~cm}^{-2}$. As shown in Fig. 8, the P-S-P membrane exhibits a high CE (>99\%) throughout 1000 cycles, indicating superior durability of the sandwich membrane. The CE increases slightly with the cycle, due to the shorter charge/discharge time with the capacity fading. Meanwhile, the EE declines only $1.3 \%$ (from $78.4 \%$ to $77.1 \%$ ) after 1000 cycles, which should be ascribed to the precipitation of $\mathrm{V}_{2} \mathrm{O}_{5}$ in the positive half-cell during long-term operation. ${ }^{\mathbf{8} 35}$ Notably, the $\mathrm{P}-\mathrm{S}-\mathrm{P}$ membrane shows excellent capacity retention ability and remains $72.7 \%$ of its initial charge capacity even after 1000 cycles, corresponding to an extremely lower capacity decay rate of $0.027 \%$ per cycle. The super longterm cycling stability clearly demonstrates that the PAN nanofiber mat protection is an efficient and robust strategy to promote the use of SPEEK membrane in VFB.

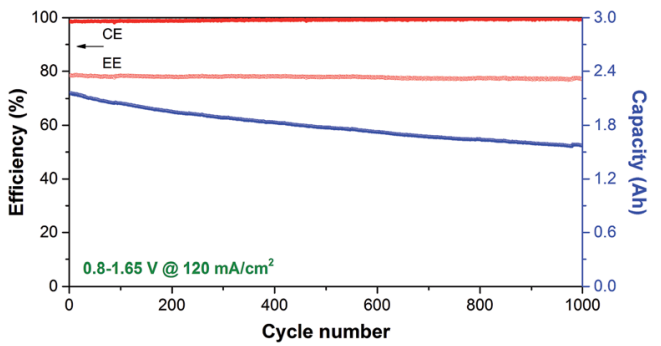

Fig. 8 Super long-term cycling stability of the P-S-P membrane at a current density of $120 \mathrm{~mA} \mathrm{~cm}^{-2}$. 

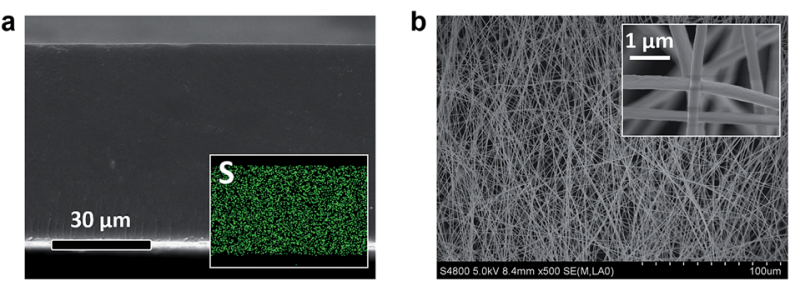

Fig. 9 Morphology of the P-S-P sandwich membrane after super long-term cycling stability test: (a) cross-section SEM and $S$ element mapping images of the SPEEK membrane, (b) SEM images of the PAN nanofiber mat.

The micro morphology of the P-S-P membrane was analyzed by SEM after above lifespan test. The three parts of the sandwich membrane can be easily separated. As shown in Fig. 9a, the SPEEK membrane shows dense cross-section structure with evenly distributed $\mathrm{S}$ element (from $-\mathrm{SO}_{3}{ }^{-}$), suggesting that the SPEEK membrane does not suffer serious damage during longterm operation. The PAN nanofiber mat also remains unchanged fiber morphology (Fig. 9b) as compared with the fresh one (Fig. 3c), indicating the excellent chemical/ mechanical stability of PAN fiber in the harsh vanadium electrolyte. This metric is beneficial for the PAN nanofiber mat to protect any other nonfluoride PEMs for highly efficient and durable use in long-life VFB.

\section{Conclusions}

In summary, a thin layer PAN nanofiber mat was prepared by electrospinning method and used as a protective layer for the SPEEK membrane in VFB. The average fiber diameter, distance between the fibers and porosity of the PAN nanofiber mat is $300 \mathrm{~nm}, 1-8 \mu \mathrm{m}$ and 0.91 , respectively. To fabricate a $\mathrm{P}-\mathrm{S}-\mathrm{P}$ sandwich membrane, the three parts are stacked together by physical contact. The PAN nanofiber mat can protect the SPEEK membrane through three aspects: (1) relax the stress from the sealing gasket; (2) prevent the SPEEK membrane from being pierced by fibers in the electrode; (3) protect the SPEEK membrane from being directly scoured by the flowing vanadium electrolyte. Meanwhile, the PAN nanofiber mat has no obvious influence on the VFB efficiency of the SPEEK membrane. As a result, the $\mathrm{P}-\mathrm{S}-\mathrm{P}$ sandwich membrane exhibits high electrolyte utilization (88.1\%@80 $\mathrm{mA} \mathrm{cm} \mathrm{cm}^{-2}$ ), excellent rate performance $\left(84.4 \%\right.$ of EE@80 $\mathrm{mA} \mathrm{cm}^{-2}$ ) and superior durability (>99\% of CE over 1000 cycles@120 mA cm ${ }^{-2}$ ) for longterm VFB operation. Moreover, this simple and robust protection strategy can be also used to promote other nonfluoride PEMs for VFB.

\section{Conflicts of interest}

There are no conflicts to declare.

\section{Acknowledgements}

We acknowledge the financial support from the Shenzhen Basic Research Project (No. JCYJ20150630114140630, JCYJ201703071 52754218 and JCYJ20170412170756603) and the Natural Science Foundation of Guangdong Province (No. 2016A030310025 and 2015A030313894).

\section{References}

1 B. Dunn, H. Kamath and J. M. Tarascon, Science, 2011, 334, 928.

2 Z. Yang, J. Zhang, M. C. Kintner-Meyer, X. Lu, D. Choi, J. P. Lemmon and J. Liu, Chem. Rev., 2011, 111, 3577.

3 C. P. Grey and J. M. Tarascon, Nat. Mater., 2017, 16, 45.

4 M. Skyllas-Kazacos, M. Rychcikl, R. G. Robins, A. G. Fane and M. Greens, J. Electrochem. Soc., 1986, 133, 1057.

5 M. Ulaganathan, V. Aravindan, Q. Yan, S. Madhavi, M. Skyllas-Kazacos and T. M. Lim, Adv. Mater. Interfaces, 2016, 3, 1500309.

6 P. Leung, X. Li, C. P. De León, L. Berlouis, C. J. Low and F. C. Walsh, RSC Adv., 2012, 2, 10125.

7 M. Skyllas-Kazacos, L. Cao, M. Kazacos, N. Kausar and A. Mousa, ChemSusChem, 2016, 9, 1521.

8 K. J. Kim, M. S. Park, Y. J. Kim, J. H. Kim, S. X. Dou and M. Skyllas-Kazacos, J. Mater. Chem. A, 2015, 3, 16913.

9 X. Li, H. Zhang, Z. Mai, H. Zhang and I. Vankelecom, Energy Environ. Sci., 2011, 4, 1147.

10 A. Kusoglu and A. Z. Weber, Chem. Rev., 2017, 117, 987.

11 J. Xi, Z. Wu, X. Qiu and L. Chen, J. Power Sources, 2007, 166, 531.

12 R. V. Noorden, Nature, 2014, 507, 26.

13 O. Schmidt, A. Hawkes, A. Gambhir and I. Staffell, Nat. Energy, 2017, 2, 17110.

14 V. Viswanathan, A. Crawford, D. Stephenson, S. Kim, W. Wang, B. Li, G. Coffey, E. Thomsen, G. Graff, P. Balducci, M. Kintner-Meyer and V. Sprenkle, J. Power Sources, 2014, 247, 1040.

15 M. Park, J. Ryu, W. Wang and J. Cho, Nat. Rev. Mater., 2017, 2, 16080.

16 B. Jiang, L. Wu, L. Yu, X. Qiu and J. Xi, J. Membr. Sci., 2016, $510,18$.

17 B. Jiang, L. Yu, L. Wu, D. Mu, L. Liu, J. Xi and X. Qiu, ACS Appl. Mater. Interfaces, 2016, 8, 12228.

18 T. Mohammadi and M. Skyllas-Kazacos, J. Appl. Electrochem., 1997, 27, 153.

19 S. Kim, T. B. Tighe, B. Schwenzer, J. Yan, J. Zhang, J. Liu, Z. Yang and M. A. Hickner, J. Appl. Electrochem., 2011, 41, 1201.

20 X. Wu, J. Hu, J. Liu, Q. Zhou, W. Zhou, H. Li and Y. Wu, Pure Appl. Chem., 2014, 86, 633.

21 J. Xi, Z. Li, L. Yu, B. Yin, L. Wang, L. Liu, X. Qiu and L. Chen, J. Power Sources, 2015, 285, 195.

22 J. Xi, B. Jiang, L. Yu and L. Liu, J. Membr. Sci., 2017, 522, 45.

23 D. W. Shin, M. D. Guiver and Y. M. Lee, Chem. Rev., 2017, 117, 4759.

24 C. Minke and T. Turek, J. Power Sources, 2015, 286, 247. 
25 Z. Yuan, X. Li, J. Hu, W. Xu, J. Cao and H. Zhang, Phys. Chem. Chem. Phys., 2014, 16, 19841.

26 W. Dai, Y. Shen, Z. Li, L. Yu, J. Xi and X. Qiu, J. Mater. Chem. A, 2014, 2, 12423.

27 S. Liu, X. Sang, L. Wang, J. Zhang, J. Song and B. Han, Electrochim. Acta, 2017, 257, 243.

28 Z. Li, W. Dai, L. Yu, L. Liu, J. Xi, X. Qiu and L. Chen, ACS Appl. Mater. Interfaces, 2014, 6, 18885.

29 S. Liu, L. Wang, D. Li, B. Liu, J. Wang and Y. Song, J. Mater. Chem. A, 2015, 3, 17590.

30 W. Wei, H. Zhang, X. Li, Z. Mai and H. Zhang, J. Power Sources, 2012, 208, 421.

31 L. Yu and J. Xi, ACS Appl. Mater. Interfaces, 2016, 8, 23425.

32 D. Li and Y. N. Xia, Adv. Mater., 2004, 16, 1151.
33 S. Agarwal, A. Greiner and J. H. Wendorff, Prog. Polym. Sci., 2013, 38, 963.

34 J. Xue, J. Xie, W. Liu and Y. N. Xia, Acc. Chem. Res., 2017, 50, 1976.

35 L. Wu, J. Wang, Y. Shen, L. Liu and J. Xi, Phys. Chem. Chem. Phys., 2017, 19, 14708.

36 S. Xiao, L. Yu, L. Wu, L. Liu, X. Qiu and J. Xi, Electrochim. Acta, 2016, 187, 525.

37 D. Mu, L. Yu, L. Liu and J. Xi, ACS Sustainable Chem. Eng., 2017, 5, 2437.

38 K. A. Mauritz and R. B. Moore, Chem. Rev., 2004, 104, 4535.

39 L. Wu, Y. Shen, L. Yu, J. Xi and X. Qiu, Nano Energy, 2016, 28, 19. 